\title{
Newborn splenic volumes vary under different malaria endemic conditions
}

\author{
J A CORKILL, ${ }^{*}$ B J BRABIN,$\dagger$ D F MACGREGOR $\ddagger$ M P ALPERS, $\dagger$ AND R D G MILNER* \\ ${ }^{*}$ Department of Paediatrics, University of Sheffield, Children's Hospital, Sheffield, †Papua New Guinea \\ Institute of Medical Research, Madang, and $¥$ Goroka Base Hospital, Eastern Highlands Province, Papua \\ New Guinea
}

SUMMARY Ultrasound was used to measure newborn splenic dimensions and calculate the volumes in a malarious and a non-malarious region of Papua New Guinea. The median splenic volume of infants born in Madang, where malaria transmission is high throughout the year, was $5 \cdot 2 \mathrm{~cm}^{3} / \mathrm{kg}$, while that of infants born in Goroka, where malaria is not endemic, was $2 \cdot 6 \mathrm{~cm}^{3} / \mathrm{kg}$. The cause of this difference is unknown, but possible explanations include fetal exposure to malaria antigens in utero and the high incidence of inherited red cell disorders in the malarious regions of Papua New Guinea.

In 1956 Bruce-Chwatt reported that the mean spleen weight of newborn African infants was one and a half times greater than that of European infants. ${ }^{1}$ An association with holoendemic malaria was suggested, and as congenital malaria is rare, it was hypothesised that parasite antigens or specific fractions of maternal antibody could cross the placenta to cause stimulation and proliferation of the fetal spleen. More recently, the offspring of mice infected with Plasmodium berghei were shown to have increased spleen to body weight ratios compared with controls. ${ }^{2}$ Splenic enlargement occurred without fetal parasitaemia, and the authors postulated that transplacental passage of soluble malaria antigens may occur.

These two studies, both using postmortem findings, suggest that fetal spleen size may be increased in association with maternal malaria. To our knowledge, there are no data on newborn spleen size in live infants born under different malaria endemic conditions. Clinical examination is inadequate for detecting mild degrees of splenomegaly, but recently ultrasound has been used successfully to estimate splenic volume in neonates. ${ }^{3}$

The aim of this study was to measure newborn splenic volumes in Papua New Guinea using ultrasound, and to compare results from a coastal region with year round malaria transmission with those from a highland region where malaria is not endemic. Cord sera were collected to measure concentrations of total IgM and malaria specific IgM, as an indicator of prenatal antigenic stimu- lation, and passively acquired malaria specific $\mathrm{IgG}$, as an indicator of maternal malaria experience. In Madang, cord and maternal haematological indices were also studied.

\section{Subjects and methods}

SUBJECTS

Splenic volumes were measured on singleton infants born at 37-41 weeks' gestation at Madang General Hospital and Goroka Base Hospital. Gestational age was assessed by the method of Dubowitz et al. ${ }^{4}$ Approval was obtained from the local ethical committee and the mother's permission was sought to measure the baby's spleen.

\section{STUDY AREAS}

Madang is on the north coast of Papua New Guinea in an area with a high level of malaria transmission throughout the year. The overall prevalence of malaria in rural Madang varies from $35 \%$ to $43 \%$ (all species, all ages) the contribution by each species being $P$ falciparum $70 \%, P$ vivax $25 \%$, and $P$ malariae $5 \%$. In urban Madang, malaria incidence is lower due to decreased vector transmission and improved access to health services. Goroka is in the Eastern Highlands Province at an altitude of 1650 metres. Early studies found no evidence of malaria in this region, but it now occurs sporadically as a result of development and increased communication with coastal areas. ${ }^{6}$ 
SPLENIC VOLUME MEASUREMENTS

The ultrasonic apparatus used in both hospitals was a Toshiba Sonolayergraph SAL-22A (Toshiba Corporation, Japan), which is a real time linear scanner with a $3.5 \mathrm{MHz}$ transducer and distance caliper. The calibration was checked before starting the study. Ultrasonography was carried out within 24 hours of birth.

To estimate splenic volume, the infant was placed in the right lateral position, and the spleen visualised in the left upper quadrant. After adjustment to give the optically largest section area in the longitudinal and transverse plane, the organ was measured as length (L) and depth $\left(D_{L}\right)$, and breadth (B) and depth $\left(D_{B}\right)$. The splenic volume was calculated using the volume formula for an ellipsoid:

$$
\text { Splenic volume }=0.523 \mathrm{~L} \times \mathrm{B} \times \frac{\mathrm{D}_{\mathrm{L}}+\mathrm{D}_{\mathrm{B}}\left(\mathrm{cm}^{3}\right)}{2}
$$

BLOOD SAMPLING AND LABORATORY PROCEDURES Cord blood samples were obtained immediately after delivery of the placenta. Serum was separated by centrifugation, and stored at $-40^{\circ} \mathrm{C}$ until analysed. Thick and thin blood films were prepared from maternal peripheral blood, placental blood, and cord blood. These were examined for malaria parasites after staining with Giemsa. Cord serum total IgM concentrations were measured by single radial immunodiffusion using commercial goat antiserum to human IgM and a World Health Organisation reference serum. ${ }^{7}$ The lower limit of detectability was $0.02 \mathrm{~g} / \mathrm{l}$. Malaria specific IgG and IgM concentrations were measured by an enzyme linked immunoadsorbent assay (ELISA) technique using a sonicate of $P$ falciparum infected red blood cells as the malaria antigen. ${ }^{8}$

In Madang, cord and maternal blood samples were also collected in tubes coated with edetic acid. The haemoglobin concentration was estimated by the cyanomethaemoglobin method, the haematocrit by a microhaematocrit method, and the mean corpuscular haemoglobin concentration was calculated.

\section{DATA FROM POSTMORTEM EXAMINATION}

In order to obtain an estimation of normal spleen size, the spleen weights of 48 infants who were stillborn or died within 24 hours of delivery were recorded from the Sheffield Children's Hospital postmortem book. The specific gravity of splenic tissue is approximately one (by Archimedes principle), therefore the splenic weight gives an approximate estimation of splenic volume.

\section{STATISTICAL METHODS}

The Student's $t$ test was used for comparison of means, and the Mann-Whitney test for comparison of medians. Correlation coefficients were estimated by linear regression.

\section{Results}

Splenic volume measurements were obtained from 20 infants in Madang and 41 infants in Goroka. The frequency distributions of splenic volume $/ \mathrm{kg}$ birth weight are shown in the figure. The Goroka distribution is concentrated towards lower values compared with the Madang distribution, with little overlap. The median splenic volumes, lengths, breadths, and depths and interquartile ranges are shown in the table. The median splenic volume from Madang was double that from Goroka (MannWhitney test, $\mathrm{p}<0.0001)$. No infant had a palpable

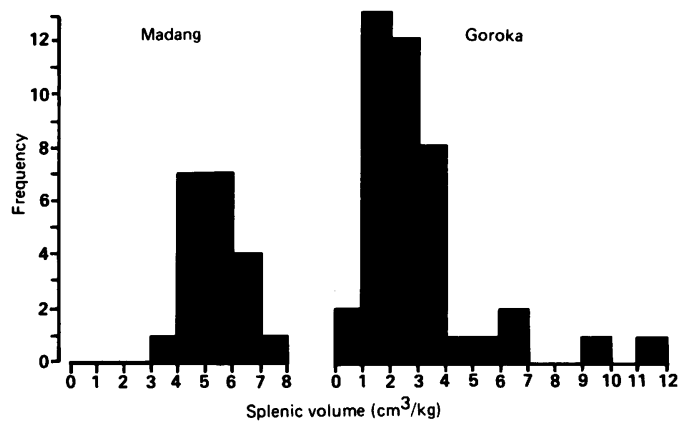

Figure Frequency distribution of splenic volume/kg birth weight.

\begin{tabular}{|c|c|c|c|c|c|c|}
\hline Source & $\begin{array}{l}\text { No of } \\
\text { infants }\end{array}$ & $\begin{array}{l}\text { Splenic } \\
\text { volume }\left(\mathrm{cm}^{3}\right)\end{array}$ & $\begin{array}{l}\text { Splenic volumel } \\
\text { kg birth weight } \\
\left(\mathrm{cm}^{3} / \mathrm{kg}\right)\end{array}$ & $\begin{array}{l}\text { Splenic } \\
\text { length }(\mathrm{mm})\end{array}$ & $\begin{array}{l}\text { Splenic } \\
\text { breadth }(\mathrm{mm})\end{array}$ & $\begin{array}{l}\text { Splenic } \\
\text { depth }(\mathrm{mm})\end{array}$ \\
\hline $\begin{array}{l}\text { Madang* } \\
\text { Goroka* } \\
\text { Sheffield† }\end{array}$ & $\begin{array}{l}20 \\
41 \\
48\end{array}$ & $\begin{array}{c}14 \cdot 5(13 \cdot 3-18 \cdot 3) \\
7.7(4 \cdot 3-10 \cdot 8) \\
6 \cdot 5(3 \cdot 6-10 \cdot 5)\end{array}$ & $\begin{array}{l}5 \cdot 2(4.6-6 \cdot 0)^{*} \\
2.6(1.5-3 \cdot 5) \\
2 \cdot 8(1.9-3.6)\end{array}$ & $\begin{array}{l}40(36-45) \\
37(32-42)\end{array}$ & $\begin{array}{l}32(29-35) \\
22(17-30)\end{array}$ & $\begin{array}{l}24(21-25) \\
16(14-21)\end{array}$ \\
\hline
\end{tabular}

Table Median splenic volume, length, breadth, and depth (interquartile range in parentheses)

*Mann-Whitney test, $\mathrm{p}<0 \cdot 0001$; †data from postmortem examination. 
spleen nor clinical evidence of perinatal infection. Median splenic volume measurements did not differ in offspring born of primigravidae and multigravidae, and no difference was observed in values from neonates who were small for gestational age and appropriate for gestational age. The mean birth weight in Madang was $3050 \mathrm{~g}$ compared with $3120 \mathrm{~g}$ in Goroka.

Cord sera were collected from 20 infants in Madang, and 22 out of 41 infants in Goroka. Small amounts of IgM were detected in all samples. The median cord serum total IgM concentration from Madang was $0.045 \mathrm{~g} /$ l (interquartile range 0.034 $0 \cdot 057$ ); this was not significantly different from that from Goroka: 0.052 g/l (interquartile range: 0.041$0 \cdot 065$ ). Splenic volume per $\mathrm{kg}$ body weight was negatively associated with cord serum total IgM concentration but the correlation was not significant in Madang or Goroka. All 20 cord sera from Madang were seropositive for malaria specific $\mathrm{IgG}$, compared with two out of 22 cord sera from Goroka. No cord serum was positive for malaria specific IgM antibody. Maternal parasitaemia was found in two cases from Goroka, and five from Madang. No cord blood sample had demonstrable parasitaemia. The splenic volumes of the offspring of parasitised mothers were not significantly different from those of uninfected mothers.

In Madang, the mean (SD) cord haemoglobin concentration was 129 (16) g/l, the mean cord haematocrit was $44(6.4) \%$, and the mean cord mean corpuscular haemoglobin concentration was 297 (19) g/l. The mean maternal haemoglobin concentration was $104(22) \mathrm{g} / \mathrm{l}$, the mean maternal haematocrit was $35(4.5) \%$, and the mean maternal mean corpuscular haemoglobin concentration was $306(27) \mathrm{g} / \mathrm{l}$.

When the different haematological variables were compared with newborn splenic volume there was a significant positive correlation only for cord haemoglobin $(\mathrm{r}=0 \cdot 45, \mathrm{p}<0 \cdot 05)$.

\section{Discussion}

The main finding of this study was that newborns from a malarious coastal region of Papua New Guinea have significantly larger spleens than those from a non-malarious highland region. Comparison with British data from postmortem examinations suggests that the highland infants have normal spleens, whereas the coastal infants have subclinical splenomegaly.

Measurements in Goroka were made by DFM and in Madang by JAC. Circumstances made it impossible to assess interobserver variation, so we cannot entirely exclude the possibility that the observed difference in splenic volumes was due to interobserver error. Identical techniques of measurement were used in the two centres, however, a clear outline of the spleen was obtained, and as splenic measurements from Madang were enlarged in every dimension compared with those from Goroka, it is likely that the observations are genuine.

In both hospitals it was routine practice to clamp the umbilical cord within $\mathbf{3 0}$ seconds of delivery, so variation in splenic volumes should not be due to differences in blood volume.

We do not know of any other data on spleen size in newborns in Papua New Guinea, but some early clinical studies are of interest. Metselaar reported that $75 \%$ of infants in a holoendemic malarious area of West New Guinea (now Irian Jaya) had a palpable spleen in the first three months of life. ${ }^{9}$ Mackerras and Aberdeen also commented on the high number of large spleens in very young children on the north coast of Papua New Guinea, and suggested that 'many infants may be born with large spleens'. ${ }^{10}$ Clinical splenomegaly was not found in newborns in the present study, even though the median splenic volume in Madang was double that in Goroka. It is generally accepted that the spleen must be twice normal in size to be palpable, but it is unclear whether this refers to length or volume.

The aetiology of newborn splenic enlargement in the coastal region is unclear. The fetal spleen has immunological and haematological functions, so mechanisms in both these categories should be considered. A recent study by Desowitz suggests that maternal malaria may cause stimulation of the fetal immune system. ${ }^{11} \mathrm{He}$ showed that the $P$ falciparum specific blastogenic response of cord blood lymphocytes from infants born in Madang was 4.5 times greater than that of cord blood lymphocytes from infants born in Hawaii where malaria transmission does not occur. Possible mechanisms for immune stimulation include: (a) transplacental passage of soluble malaria antigens; (b) asymptomatic congenital malaria; (c) idioanti-idiotype networking in the fetus after acquiring maternal antiplasmodial IgG antibody; and (d) transfer of maternal lymphocytes and/or activated macrophages. Whether immune stimulation by any of these mechanisms would result in an increase in fetal spleen size is unknown.

In highly endemic malarious regions pregnant women are particularly susceptible to malaria because pregnancy appears to interfere with the immune response to the disease. ${ }^{12}$ Five Madang women had parasitaemia at delivery, and all the Mandang cord sera contained passively acquired malaria specific IgG, indicating a high degree of 
maternal exposure to the disease. Splenic volumes did not differ in the offspring of parasitised and nonparasitised mothers, however, and the four Goroka cases with evidence of maternal malaria infection (two with maternal parasitaemia and two with passively acquired malaria specific $\mathrm{IgG}$ ) did not have enlarged spleens.

Cord serum total IgM and malaria specific IgM concentrations were measured as a possible indicator of prenatal immune stimulation. No significant difference in total $\operatorname{IgM}$ concentration between Madang and Goroka was found, and malaria specific IgM was not detected; however, the high concentration of passively acquired malaria specific IgG in cord serum may interfere with the ELISA for malaria specific IgM. These data do not support the hypothesis that fetal immune stimulation is occurring, but it is possible that splenic enlargement could occur by immunological mechanisms independent of antibody production.

Fetal splenomegaly could also result from haematological mechanisms. Erythropoiesis in the spleen normally ceases before birth, but may resume in certain pathological conditions such as haemolytic anaemia. ${ }^{13}$

In Madang the mean cord haemoglobin concentration was $129 \mathrm{~g} / \mathrm{l}$, the mean cord haematocrit was $44 \%$, and the mean cord mean corpuscular haemoglobin concentration was $297 \mathrm{~g} / \mathrm{l}$. These values are low in comparison with the normal ranges given for developed countries (cord haemoglobin 135-190 g/l, cord haematocrit $44-64 \%,{ }^{14}$ and cord mean corpuscular haemoglobin concentration $300-350 \mathrm{~g} / \mathrm{l}^{15}$ ). Also a significant correlation was found between the cord haemoglobin concentration and the newborn splenic volume $(r=0 \cdot 45, p<0 \cdot 05)$. It therefore seems plausible that the observed splenomegaly in Madang could be the result of a haematological disturbance leading to haemolysis or an increased need for erythropoiesis, or both. Possible causes for this include inherited red cell disorders and malaria.

The precise pathogenesis of malarial anaemia is uncertain, but it is thought to involve both defective production and increased destruction of red cells, ${ }^{16}$ and it has been suggested that the immunological destruction of non-parasitised cells may occur. ${ }^{17}$ Soluble malaria antigens may be non-specifically absorbed on to the surface of normal erythrocytes, and binding of antibodies to these antigens may trigger complement or cell dependent effector mechanisms resulting in removal of erythrocytes. ${ }^{18}$ Placental transfer of soluble antigens and corresponding maternal antibodies could in this way cause fetal haemolysis and anaemia.

Several inherited red cell disorders are common in malarious areas of Papua New Guinea, particularly $\alpha$ thalassaemia, ovalocytosis, and glucose-6phosphate dehydrogenase deficiency. In the Eastern Highlands only $9 \%$ of individuals were found to have $\alpha$ thalassaemia deletions, ${ }^{19}$ but around Madang $97 \%$ have the genotype $-\alpha / \alpha \alpha$ or $-\alpha /-\alpha .^{20}$ The incidence of high frequency hereditary ovalocytosis is between $11-30 \%$ in the Madang area but is rare in Highlands. ${ }^{21}$ Glucose-6-phosphate dehydrogenase deficiency was found in $10-20 \%$ of males in Madang, and in $1 \%$ of Eastern Highlands males. ${ }^{20}$ These inherited red cell disorders could cause a degree of anaemia in the newborn which might explain the increased splenic volumes found in coastal Papua New Guinea. A study in Polynesians on the influence of $\alpha$ thalassaemia on haematological indices found that the mean cord haemoglobin from $\alpha$ thalassaemia homozygotes (genotype $-\alpha /-\alpha$ ) was $13 \mathrm{~g} / \mathrm{l}$ less than that of normal individuals $(p=0.01)$, while that of $\alpha$ thalassaemia heterozygotes (genotype $-\alpha / \alpha \alpha)$ was $4 \mathrm{~g} / 1$ less $(\mathrm{p}<0 \cdot 05) .22$ Whether $\alpha$ thalassaemia alone would be sufficient to explain the anaemia and the increased splenic volumes found in Madang is uncertain. Another possibility is that fetal splenic enlargement could occur in association with maternal anaemia by the transplacental passage of a haemopoietic stimulus. Under these circumstances, however, high cord haemoglobin concentrations would be expected rather than the low concentrations found in this study.

Further work should be aimed at confirmation of these findings and differentiation between haematological and immunological causes of newborn splenic enlargement.

JAC wishes to thank the Isle of Man Postgraduate Medical Centre, the Edward Boyle Memorial Trust, the Papua New Guinea Institute of Medical Research, and the Foulkes Foundation for financial support, and Mrs G Darwin for tuition in ultrasonography. DFM wishes to thank the midwives at Goroka Base Hospital for cord blood collections, and $\mathrm{Dr} \mathrm{J}$ Richens for tuition in ultrasonography. The help of Dr Mohan, Dr C Witt, Mr A Raiko, Dr K Forsyth, and Mrs D Parsons is gratefully acknowledged.

\section{References}

1 Bruce-Chwatt LJ. Biometric study of spleen- and liver-weights in Africans and Europeans, with special reference to endemic malaria. Bull WHO 1956;15:513-48.

2 Odoula AMJ, Holbrook TW, Galbraith RM, Bank H, Spicer SS. Effects of malaria (Plasmodium berghei) on the maternalfoetal relationship in mice. J Protozool 1982;29:77-81.

3 Dittrich M, Milde S, Dinkel E, Baumann W, Weitzel D. Sonographic biometry of liver and spleen size in childhood. Pediatr Radiol 1983;13:206-11.

4 Dubowitz LMB, Dubowitz V, Goldberg C. Clinical assessment of gestational age in the newborn infant. $J$ Pediatr 1970;77:1-10.

5 Cattani JA, Tulloch JL, Vrbova H, et al. The epidemiology of malaria in a population surrounding Madang, Papua New Guinea. Am J Trop Med Hyg 1986;35:3-15. 
${ }^{6}$ Radford AJ, van Leeuwen H, Christian SH. Social aspects in the changing epidemiology of malaria in the highlands of New Guinea. Ann Trop Med Parasitol 1976;70:11-23.

${ }^{7}$ Mancini G, Carbonara AO, Heremans JF. Immuno-chemical quantitation of antigens by single radial immunodiffusion. Immunochemistry 1965;2:235-56.

${ }^{8}$ Voller A, Cornille-Broger R, Storey J, Molineaux L. A longitudinal study of Plasmodium falciparum malaria in the West African savanna using the ELISA technique. Bull WHO 1980;58:429-38.

${ }^{9}$ Metselaar D. Spleens and holoendemic malaria in West New Guinea. Bull WHO 1956;15:635-49.

${ }^{10}$ Mackerras IM, Aberdeen JBC. Malaria survey at Wewak. New Guinea. Med J Aust 1946;2:763-71.

11 Desowitz RS. Prenatal immune priming in malaria: antigenspecific blastogenesis of cord blood lymphocytes from neonates born in a setting of holoendemic malaria. Ann Trop Med Parasitol 1988;82:121-6.

12 Brabin BJ. An analysis of malaria in pregnancy in Africa. Bull WHO 1983;61:1005-16.

13 Thompson RB. Disorders of the blood. A textbook of clinical haematology. London: Churchill Livingstone, 1977.

14 Dacie JV, Lewis SM. Practical haematology. 5th ed. London: Churchill Livingstone, 1975.

15 Oski FA, Naiman JL. Haematologic problems in the newborn. 3rd ed. New York: WB Saunders Company, 1982.
16 Weatherall DJ, Abdalla S. The anacmia of Plasmodium falciparum malaria. Br Med Bull 1982;38:147-51.

17 Facer Ca, Bray RS, Brown J. Direct Coombs antiglobulin reactions in Gambian children with Plasmodium falciparum malaria. I. Incidence and class specificity. Clin Exp Immunol 1979:31:119-27.

${ }_{18}$ Ristic M, Abroise-Thomas P, Kreier JP. Malaria and babesiosis. Amsterdam: Martinus Nijhoff Publishers, 1984.

${ }^{19}$ Flint J, Hill VS, Bowden DK, et al. High frequencies of $\alpha$ thalassaemia are the result of natural selection by malaria. Nature 1986;321:744-50.

20 Yenchitsomanus P, Summers KM, Chockkalingham C, Board PG. Characterisation of G6PD deficiency and thalassaemia in Papua New Guinea. Papua New Guinea Med J 1986:29:53-8.

${ }^{21}$ Cattani JA, Gibson FD, Alpers MP, Crane GG. Hereditary ovalocytosis and reduced susceptibility to malaria in Papua New Guinea. Trans R Soc Trop Med Hyg 1987;81:705-9.

22 Mickleson KNP, Dixon MW, Hill PJ, et al. Influence of $\alpha$-thalassaemia on haematological parameters in Polynesian patients. NZ Med J 1986;98:1036-8.

Correspondence to Professor RDG Milner, Children's Hospital, Sheffield S10 2TH.

Accepted 24 October 1988 